\title{
Simulation of space-borne tsunami detection using GNSS-Reflectometry applied to tsunamis in the Indian Ocean
}

\author{
R. Stosius ${ }^{1}$, G. Beyerle ${ }^{1}$, A. Helm ${ }^{1, *}$, A. Hoechner ${ }^{1}$, and J. Wickert ${ }^{1}$ \\ ${ }^{1}$ Deutsches GeoForschungsZentrum GFZ, Telegrafenberg, 14473 Potsdam, Germany \\ *now at: Astrium Space Transportation, 88039 Friedrichshafen, Germany
}

Received: 26 March 2010 - Accepted: 27 May 2010 - Published: 25 June 2010

\begin{abstract}
Within the German-Indonesian Tsunami Early Warning System project GITEWS (Rudloff et al., 2009), a feasibility study on a future tsunami detection system from space has been carried out. The Global Navigation Satellite System Reflectometry (GNSS-R) is an innovative way of using reflected GNSS signals for remote sensing, e.g. sea surface altimetry. In contrast to conventional satellite radar altimetry, multiple height measurements within a wide field of view can be made simultaneously. With a dedicated Low Earth Orbit (LEO) constellation of satellites equipped with GNSS-R, densely spaced sea surface height measurements could be established to detect tsunamis. This simulation study compares the Walker and the meshed comb constellation with respect to their global reflection point distribution. The detection performance of various LEO constellation scenarios with GPS, GLONASS and Galileo as signal sources is investigated. The study concentrates on the detection performance for six historic tsunami events in the Indian Ocean generated by earthquakes of different magnitudes, as well as on different constellation types and orbit parameters. The GNSS-R carrier phase is compared with the PARIS or code altimetry approach. The study shows that Walker constellations have a much better reflection point distribution compared to the meshed comb constellation. Considering simulation assumptions and assuming technical feasibility it can be demonstrated that strong tsunamis with magnitudes $(M) \geq 8.5$ can be detected with certainty from any orbit altitude within $15-25$ min by a $48 / 8$ or $81 / 9$ Walker constellation if tsunami waves of $20 \mathrm{~cm}$ or higher can be detected by spaceborne GNSS-R. The carrier phase approach outperforms the PARIS altimetry approach especially at low orbit altitudes and for a low number of LEO satellites.
\end{abstract}

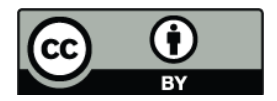

Correspondence to: R. Stosius (rstosius@gfz-potsdam.de)

\section{Introduction}

122 tsunami events have been reported for the Indian Ocean before the devastating Sumatra-Andaman or Sumatra tsunami occurred in 2004, 15 of them took by far more than 100 lives (National Geophysical Data Center, 2009). The high number of victims caused by tsunamis has desperately shown the need for a tsunami early warning system in the Indian Ocean. The waves of the Sumatra tsunami arrived at the coast within only $20 \mathrm{~min}$ after the earthquake. Any tsunami early warning system must fulfill the requirement to detect tsunami waves as soon as possible and with highest certainty to prevent false warnings. This means that tsunamis should be detected on the open sea within only $15 \mathrm{~min}$ after their generation by an earthquake or another triggering event like, e.g. a submarine slide (Brune et al., 2010). In the case of GITEWS an epicenter will be localized by a network of seismometers (Hanka et al., 2008) and GPS deformation monitoring stations (Babeyko et al., 2010; Falck et al., 2010) very quickly, but these do not provide any information if a tsunami has been generated or not. The ocean surface has therefore to be monitored for tsunami wave signatures. Pressure sensors, buoys and tide gauges are measuring sea surface height anomalies with very high accuracy in case a tsunami wave arrives at these sensors (Behrens et al., 2010). Even though the spatial distribution of these sensors has been selected carefully, the number of sensors is limited due to the high cost for development and deployment. The setup and maintenance of a large sensor network for all vulnerable regions worldwide would be extremely expensive.

Tsunami detection from space could be a valuable complement to ground based systems. Tsunamis are a global phenomenon and for global observations satellites are predestined. Tsunami waves can be detected from space as Ablain et al. (2006) have demonstrated for the Sumatra tsunami with radar altimeter (RA) data from TOPEX/POSEIDON,

Published by Copernicus Publications on behalf of the European Geosciences Union. 


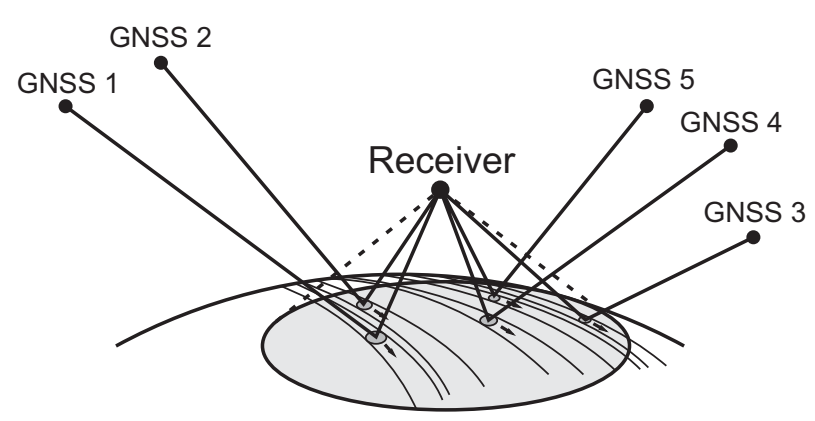

Fig. 1. Illustration of bistatic GNSS reflection geometry. GNSS signals transmitted by GNSS satellites are reflected from the Earth's surface and received by a dedicated GNSS-R receiver on board a LEO satellite. There are multiple reflection footprints forming several reflection point ground tracks within the field of view of the satellite (from Martín-Neira et al. (2002)).

Jason-1, ENVISAT, and GEOSAT Follow-On. There are only few RA satellites in space and they measure only in nadir direction. Their spatial coverage is therefore coarse and their temporal coverage is not high enough for tsunami early warning, because they do not transmit their data immediately to the ground. Martín-Neira (1993) has proposed that the GNSS-Reflectometry (GNSS-R) technique is applicable for ocean altimetry and therefore for tsunami detection from space (Martín-Neira et al., 2005). The technique uses GNSS signals that are reflected from water or ice surfaces as measurement signals. The travel time of the reflected signal compared to the direct one is a measure of the height of the reflecting surface and the reflected signal provides information about the properties of the surface (Fig. 1). GNSS-R is a passive measurement technique, which allows to build micro satellites and to arrange them as a LEO constellation intended for global and permanent altimetric and scatterometric ocean observation. In combination with a seismic sensor network and in addition to local sea surface observation sensors such a system would contribute sea surface height observations over areas of several thousand $\mathrm{km}^{2}$ and would provide the only source of information in those regions where no local sensors exist.

In this simulation study we analyse various GNSS-R LEO constellations with respect to their tsunami detection performance. First, different constellation types are compared due to their global reflection point distribution. GPS, GLONASS and Galileo signals are assumed to be available and to be receivable without any principal or technical restrictions. The detection performance for each parameter combination is calculated empirically based on 100 independent simulation runs. Six tsunamis that occurred in the Indian Ocean triggered by earthquakes with different magnitudes are investigated. The orbit parameters altitude and inclination angle are varied to show their effects on the detection performance. Four assumed altimetric sensitivities and two different GNSS-R approaches are compared.

\section{The GNSS-Reflectometry method}

In GNSS-R two altimetry approaches, the code altimetry and the carrier phase altimetry, can be distinguished. In the code altimetry or Passive Reflectometry and Interferometry System (PARIS) concept proposed by Martín-Neira (1993) the time delays between the direct and reflected signals are measured, which can be translated into absolute height of the reflecting surface at the specular point. In ground based GNSS reflection experiments above an artificial pond, height accuracies of $1 \mathrm{~cm}$ are obtained (Martín-Neira et al., 2002). Within the range of 500-1000 $\mathrm{m}$ above the reflecting water surface, height values with accuracies of $2 \mathrm{~cm}$ were found (Treuhaft et al., 2001). In a series of airplane and balloon experiments this technique was successfully applied in airborne campaigns (Garrison et al., 1998; Garrison and Katzberg, 2000; Rius et al., 2002; Cardellach et al., 2003; Ruffini et al., 2004; Nogués-Correig et al., 2007; Cardellach et al., 2009). In these experiments, sea level heights with accuracies of up to $5 \mathrm{~cm}$ as well as the relation between C/A-code correlation function and significant wave heights were determined using dedicated delay mapping GPS receivers. First observations of GNSS signal reflections from space-borne platforms were presented by Pavelyev et al. (1996) and Lowe et al. (2002). Gleason et al. (2005) report on first, promising results from the GNSS reflection experiment aboard the UK-DMC satellite. They succeeded in showing that bistatically reflected GPS signals are detectable from a LEO spacecraft and that signal characteristics are consistent with model results taking into account knowledge of sea state conditions at the places and times of the observations. For an intended in-orbit demonstrator mission PARIS IOD Martín-Neira et al. (2008) expect that the height accuracy of such a system is within $17 \mathrm{~cm}$ RMS for measurements over $100 \mathrm{~km}$ along track.

On the other hand, signatures of coherent GPS reflections at low elevation angles were observed in radio occultation data of the GPS/MET, SAC-C and CHAMP satellites (Beyerle and Hocke, 2001; Beyerle et al., 2002; Hajj et al., 2004). With a carrier phase interferometric approach the phase variation between direct and reflected signal can be translated into height variations of the reflecting surface. This only works for coherent reflections, which are limited to grazing elevation angles. In a ground based experiment from $800 \mathrm{~m}$ above the water level of lake Walchen, Bavarian Alps, the water surface height has been measured with an accuracy of $2 \mathrm{~cm}$ by using a modified commercial off-the-shelf (COTS) receiver (Helm et al., 2008). For phase measurements of the CHAMP satellite Cardellach et al. (2004) has achieved $70 \mathrm{~cm}$ height accuracy for GPS reflections from the Greenland ice sheet.

These two approaches have many advantages compared to conventional RA. Instead of RA a GNSS-R receiver aboard a LEO satellite receives reflections from many GNSS satellites at various elevation angles simultaneously. This results in a high spatial coverage of reflections. GNSS signals are 
available for free and continuously over many years which guarantees a reasonable and constant resource of measurement signals. The existing GPS is modernized by introducing new frequencies and signal codes and the GLONASS system will be completed in 2010. The number of GNSS satellites will increase due to the installation of Galileo to over 80 within the next decade. Further GNSS systems are scheduled by China (COMPASS/Beidou), Japan (QZSS) and India (IRNSS). GNSS-R is a passive measurement technique that has a low energy budget. It can therefore by applied to small affordable micro satellites like, e.g. MicroGEM (Brieß et al., 2009). Because of this, also satellite constellations are possible at comparably low costs, especially if COTS technology can be applied. With a satellite constellation the temporal coverage can be increased to fulfill given tsunami early warning requirements.

\section{Reflection point calculation}

In this study the GNSS-R LEO satellites of a constellation are represented by simulated two-line elements (TLE). To provide circular orbits, the excentricity parameter is set to minimum. The satellite positions are calculated using a SGP4 orbit propagator (Hoots and Roehrich, 1980). GNSS satellites are considered as signal transmitters. GPS and GLONASS orbit parameters are obtained from IGS broadcast ephemerides (Dow et al., 2005) and positions are calculated according to NAVSTAR (1995). In case of Galileo, simulated two-line elements (TLE) are used because this constellation is not yet operating. Kepler orbit parameters for each satellite are created from known parameters like orbit altitude, inclination angle and constellation type assuming circular orbits. Satellite positions are calculated by applying a SDP4 orbit propagator (Hoots and Roehrich, 1980). Only the 27 nominal Galileo satellites are considered, the 3 spare satellites are neglected. This simulates a realistic situation with some operational satellites occasionally not available.

The reflection points on the WGS84 ellipsoid are calculated using the double differences method by Garrison et al. (1997). The geometrical ray path length of a signal transmitted from a GNSS satellite $T$ with cartesian coordinates $\left(X_{T}\right.$, $\mathrm{Y}_{\mathrm{T}}, \mathrm{Z}_{\mathrm{T}}$ ), that touches the reflection point with polar coordinates $\left(\phi_{\mathrm{S}}, \lambda_{\mathrm{S}}\right)$ on the specular surface and that is received by a satellite $L$ with the antenna coordinates $\left(\mathrm{X}_{\mathrm{L}}, \mathrm{Y}_{\mathrm{L}}, \mathrm{Z}_{\mathrm{L}}\right)$ is given by

$$
\begin{aligned}
& \rho_{\mathrm{L}}\left(\phi_{\mathrm{S}}, \lambda_{\mathrm{S}}\right) \\
& =\sqrt{\left(\mathrm{X}_{\mathrm{L}}-\mathrm{X}_{\mathrm{S}}\right)^{2}+\left(\mathrm{Y}_{\mathrm{L}}-\mathrm{Y}_{\mathrm{S}}\right)^{2}+\left(\mathrm{Z}_{\mathrm{L}}-\mathrm{Z}_{\mathrm{S}}\right)^{2}} \\
& +\sqrt{\left(\mathrm{X}_{\mathrm{T}}-\mathrm{X}_{\mathrm{S}}\right)^{2}+\left(\mathrm{Y}_{\mathrm{T}}-\mathrm{Y}_{\mathrm{S}}\right)^{2}+\left(\mathrm{Z}_{\mathrm{T}}-\mathrm{Z}_{\mathrm{S}}\right)^{2}}
\end{aligned}
$$

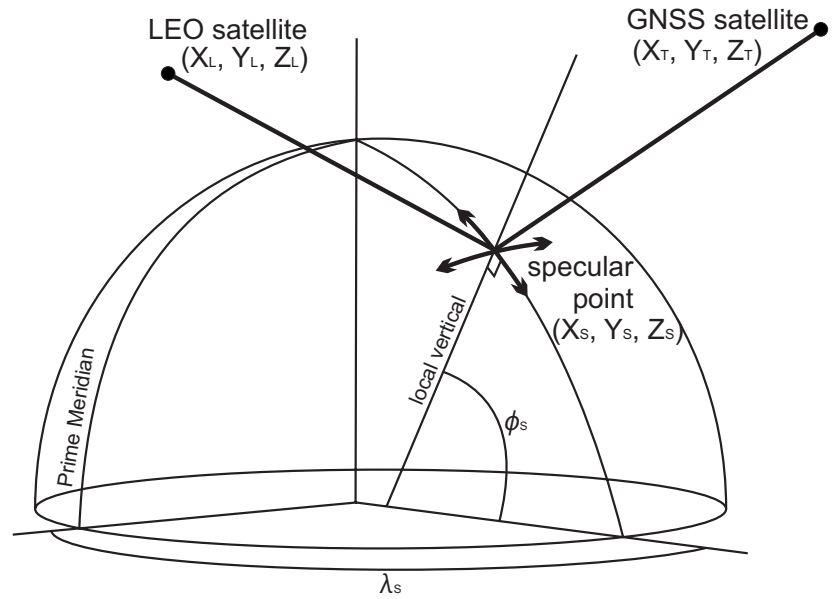

Fig. 2. Specular reflection point geometry for a GNSS signal path transmitted from a GNSS satellite T, reflected at specular point $\mathrm{S}$ and received at the LEO satellite L (from Garrison et al. (2002)).

$$
\begin{aligned}
& \mathrm{X}_{\mathrm{S}}=\frac{a^{2} \cos \phi_{\mathrm{S}} \cos \lambda_{\mathrm{S}}}{\sqrt{a^{2} \cos ^{2} \phi_{\mathrm{S}}+b^{2} \sin ^{2} \phi_{S}}} \\
& \mathrm{Y}_{\mathrm{S}}=\frac{a^{2} \cos \phi_{\mathrm{S}} \sin \lambda_{\mathrm{S}}}{\sqrt{a^{2} \cos ^{2} \phi_{\mathrm{S}}+b^{2} \sin ^{2} \phi_{\mathrm{S}}}} \\
& \mathrm{Z}_{\mathrm{S}}=\frac{b^{2} \sin \phi_{\mathrm{S}}}{\sqrt{a^{2} \cos ^{2} \phi_{\mathrm{S}}+b^{2} \sin ^{2} \phi_{\mathrm{S}}}}
\end{aligned}
$$

with $a$ and $b$ as major and minor axes length of the WGS84 ellipsoid, respectively. For a given pair of LEO and GNSS satellite positions, this path length is minimized by varying the polar coordinates of the specular point $\mathrm{S}$. The reflection point geometry is shown in Fig. 2.

All GNSS reflection points from GNSS satellites that are visible from the LEO satellite position are taken into account. This means that all GNSS signals reflected from the WGS84 ellipsoid that would reach the LEO satellite positions geometrically are assumed to be technically receivable. The issue of technical feasibility is discussed in more detail in Sect. 5. For any LEO satellite of the constellation, reflection points are calculated with 1 min temporal resolution over a one day period. In this period there are about 2 repetitions of any GNSS system and it is long enough to cover all observable areas at least 2 times with a minimum of 4 LEO satellites evenly distributed on 2 orbit planes if a maximum footprint size is assumed.

\section{Comparison of GNSS-R LEO constellations}

According to Soulat et al. (2005) most seismic driven tsunamis occur within $\pm 60^{\circ}$ latitude. A satellite constellation for tsunami detection should cover at least this area 
Table 1. Four constellations with 18 satellites at $900 \mathrm{~km}$ altitude but with different inclination angles and number of orbits. The constellation in row 3 consists is a combination of two 9/3 Walker constellations with different inclination angles.

\begin{tabular}{lccc}
\hline type & satellites & orbits & inclination \\
\hline Walker & 18 & 3 & $60^{\circ}$ \\
Walker & 18 & 3 & $120^{\circ}$ \\
Walker & 9 & 3 & $40^{\circ}$ \\
& 9 & 3 & $80^{\circ}$ \\
meshed comb & 9 & 9 & $60^{\circ}$ \\
& 9 & 9 & $120^{\circ}$ \\
\hline
\end{tabular}

but also at higher latitudes tsunamis triggered by submarine slides may occur (Brune et al., 2009). A space-borne tsunami early warning system should also cover higher latitudes. There, a lower temporal coverage is sufficient because slides are very rare and they will trigger only local tsunamis. They are less dangerous because the regions in high latitudes are not densely populated.

For global ocean observations a LEO constellation must provide an optimum spatial coverage of GNSS reflections. Walker constellations (Walker, 1984) are designed to provide a good global coverage, but near the Equator this coverage is reduced. The meshed comb constellation (Jackson, 1998) solves this by arranging all satellites along the Equator at the same moment. A Walker constellation consists of different evenly distributed circular orbit planes that have the same inclination angle and a certain number of satellites that are evenly distributed on each orbit plane. The satellites on adjacent orbit planes are phase shifted to each other. For example a $18 / 3$ constellation consists of 18 satellites that are distributed evenly on 3 orbit planes with 6 satellites on each plane. The 6 satellites follow each other every $60^{\circ}$. With 3 orbit planes the phase shift is $60^{\circ} / 3=20^{\circ}$. The satellites follow prograde orbits if the inclination angle is $<90^{\circ}$ and retrograde orbits if this angle is $>90^{\circ}$ (Larson and Wertz, 1995). In the meshed comb constellation, each satellite has its own orbit plane and the satellites on adjacent orbit planes move in opposite directions. This means that half of the satellites follow prograde orbits while the others follow retrograde orbits.

To find out which of these constellations should be used for global GNSS-R observations, the reflection point coverages of four different constellations with 18 satellites each at $900 \mathrm{~km}$ orbit altitude are compared (Table 1). The number of reflection points within each grid cell of a $1^{\circ}$ spaced spatial grid are counted and cumulated for each degree of latitude. Figure 3 shows the global latitude distributions of reflection points of the four constellations. The prograde and retrograde 18/3 Walker constellations show similar distributions with high values between $\pm 60^{\circ}$ latitude and a strong decrease when advancing to higher latitudes. In the com-

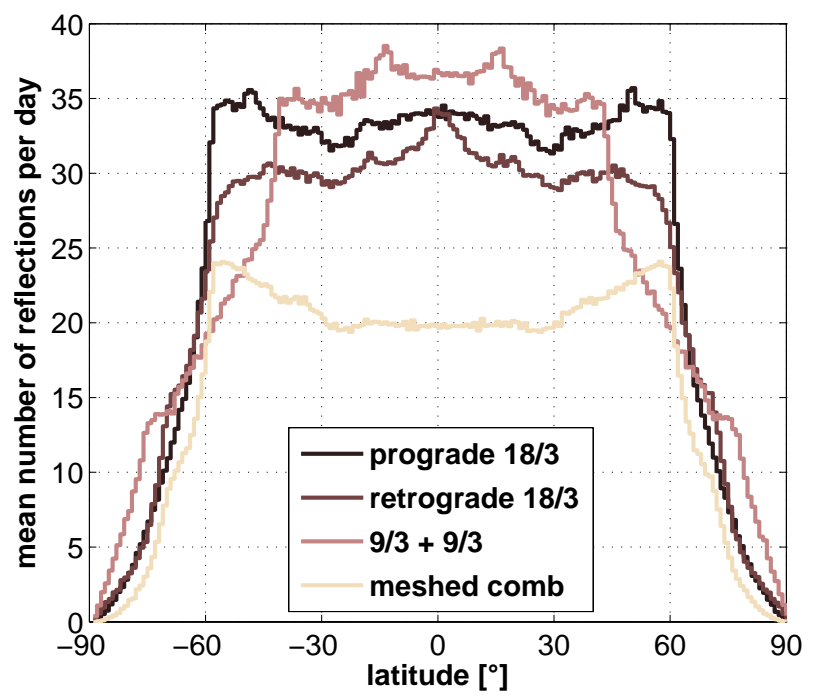

Fig. 3. Latitude distributions of reflection points over one day for different 18 satellite constellations at $900 \mathrm{~km}$ altitude (Table 1) using GPS as signal source. (a) 18/3 Walker constellation, 60 inclination angle, (b) $18 / 3$ Walker constellation, $120^{\circ}$ inclination angle (retrograde), (c) $9 / 3$ Walker constellations with $40^{\circ}$ and $80^{\circ}$ inclination angle, (d) meshed comb constellation.

bined 9/3 Walker constellations with different inclination angles the high latitudes are represented stronger and the low latitudes between $\pm 40^{\circ}$ show a very high number of reflection points. In contrast to this the meshed comb constellation overrepresents latitudes between $30^{\circ}$ and $60^{\circ}$ and the overall number of reflections is significantly lower as compared to the three Walker constellation types.

From a scientific point of view, only the reflection point coverage is relevant, but if a decision between these constellations has to be made, also other driving factors like the costs to install such a system in space may be considered. The number of satellites is the same for all scenarios but the number of necessary launches differs significantly. In the constellation prograde $18 / 3$ constellation there are 6 satellites distributed on 3 orbit planes so that the entire constellation may be set up with 3 launches only. The same is true for the retrograde constellation, but retrograde orbits are much more expensive due to a much higher amount of fuel needed because the Earth' rotation moment has to be overcome during launch (Larson and Wertz, 1995). For the combined 9/3 constellations at least 6 launches are necessary. In the meshed comb constellation every satellite is on its own orbit plane and half of the satellites need to be in a retrograde orbit which means up to 18 launches to install such a constellation. Even though the number of launches may be reduced by using temporary altitude separation like it is demonstrated by the COSMIC constellation (Anthes et al., 2008) the prograde Walker constellation is most favorable and will be used throughout our simulation study. 


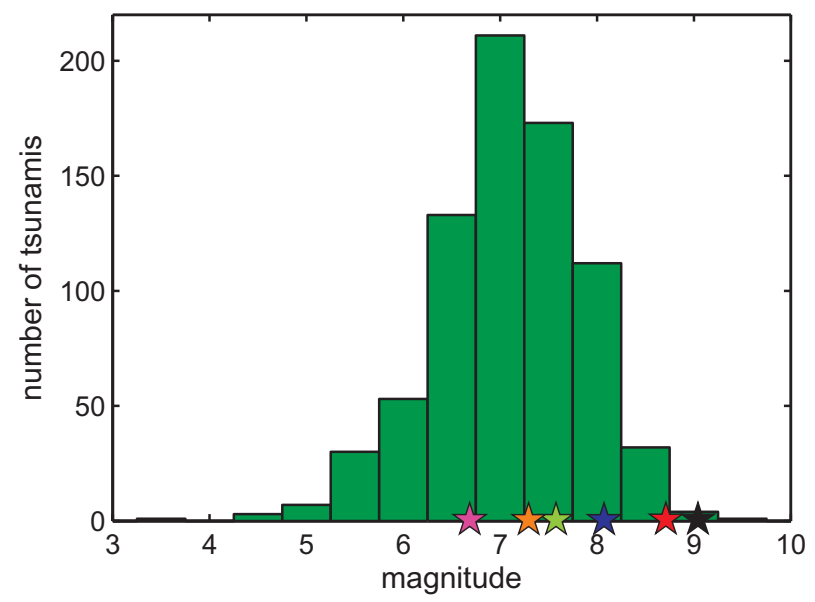

Fig. 4. Histogram of magnitudes for historical earthquakes worldwide that caused a tsunami within the period 1900-2008 based on events listed in the NGDC database (National Geophysical Data Center, 2009). The colored stars correspond to the events listed in Table 2 and their detection probability functions are shown in Fig. 9.

\section{Tsunami detection simulation}

The Sumatra earthquake on 26 December 2004 had $M$ between 9.0 (National Geophysical Data Center, 2009) and 9.3 (Stein and Okal, 2005) and generated a tsunami that took more than 225000 lives. On 28 March 2005 another strong earthquake of $M 8.5$ near the island of Nias occurred. The earthquake and the tsunami that followed killed about 1300 people (ITIC, 2005). The histogram of historic tsunamis worldwide (Fig. 4) shows that events like the Sumatra and Nias tsunami are very rare, but their effects are dramatic. In this study we are interested in the question at which minimum magnitude of an earthquake, a tsunami can be sensed by a GNSS-R LEO constellation with certainty and what are the parameters that have a major impact on the detection performance.

The detection performances of various prograde Walker constellations are calculated for six tsunami events with different earthquake magnitudes (Table 2). These tsunamis are modeled using code TUNAMI-N2 (Imamura et al., 1997) which implements nonlinear shallow water equations and computes sea surface height anomalies. Tsunami model output comprises $70^{\circ}$ to $110^{\circ}$ longitude and $-15^{\circ}$ to $25^{\circ}$ latitude with 5 arcmin spacing and $1 \mathrm{~min}$ temporal resolution over a period of $3 \mathrm{~h}$ after the earthquake. Initial condition for tsunami modeling is vertical sea floor displacement. For the Sumatra event, this has been obtained from the GPS-based earthquake source inversion by Hoechner et al. (2008), and the same technique has been applied for the Nias event. Geodetic inversions are especially adequate for tsunami modeling, since they are better able to capture the coseismic sea floor deformation due to an earthquake than
Table 2. Historical tsunami events in the Indian Ocean taken from ${ }^{a}$ Murty and Rafiq (1991), b ITIC (2005), c National Geophysical Data Center (2009), and ${ }^{\mathrm{d}}$ Kanamori (2006). The events in rows 3 and 4 are the same but modeled with different magnitudes found in the literature. Colors correspond to those in Figs. 4 and 9.

\begin{tabular}{llcll}
\hline$M$ & longitude & latitude & date & color \\
\hline 9.1 & 95.8 & 3.3 & 26 Dec 2004 $^{\mathrm{d}}$ & black \\
8.5 & 97.0 & 2.1 & 28 Mar 2005 & red \\
8.1 & 92.5 & 12.5 & 26 Jun 1941 & blue \\
7.6 & 92.5 & 12.5 & 26 Jun 1941 & green \\
7.1 & 94.7 & 6.1 & 23 Aug 1936 & orange \\
6.7 & 99.6 & -1.6 & 10 Apr 2005 & magenta \\
\hline
\end{tabular}

traditional seismic inversions (Sobolev et al., 2007). The smaller earthquakes are computed using simpler one-fault models. Figure 5 shows sea surface heights $15 \mathrm{~min}$ after the earthquake for the four strongest tsunamis listed in Table 2.

To simulate a GNSS-R sea surface observation during the tsunami events, GPS, GLONASS and Galileo signals are used in combination. Their ephemerides were obtained for those days the tsunamis have happened. For the events that occurred in 1936 and 1941 the same ephemerides as for the Nias event are used. The reflection points form tracks of reflection measurements across the sea surface (Fig. 1). When passing over the tsunami model grid the measurable height anomalies are extracted from the grid cells at discrete time steps of 1 min, which is illustrated in Fig. 6.

Typically the waves of a strong tsunami in the deep sea region propagate at about $700 \mathrm{~km} / \mathrm{h}$ and have a wavelength of $50-200 \mathrm{~km}$ but only about $50 \mathrm{~cm}$ of amplitude (NOAA/IOC/ITIC/LDG, 2002). Right after the earthquake the tsunami wave height is highest. While the energy induced by the earthquake spreads over an expanding tsunami area the maximum wave height decreases at a rate of about $1 / \sqrt{r}$, and $r$ denoting the radius of the area, in case the water depth persists. When the tsunami waves reach the marine shelf region, the water depth decreases and the wave height increases. To detect tsunamis even within the deep sea region a GNSS-R system must detect waves of only a few decimeters.

The assumption that a GNSS-R system is able to detect tsunami waves of $\geq 20 \mathrm{~cm}$ (Germain and Ruffini, 2006) is technically very ambitious. There are many error sources that will influence the GNSS signal on its way from the transmitter through the atmosphere over the reflecting surface to the receiver. The GNSS position has to be known very precisely and the clock error of the transmitter has to be corrected. The direct and reflected signal path follow different ways through the ionosphere and especially the troposphere. Their impact on the GNSS signal is addressed in radio occultation research but not fully understood yet (Syndergaard, 2000; Gorbunov, 
(a)
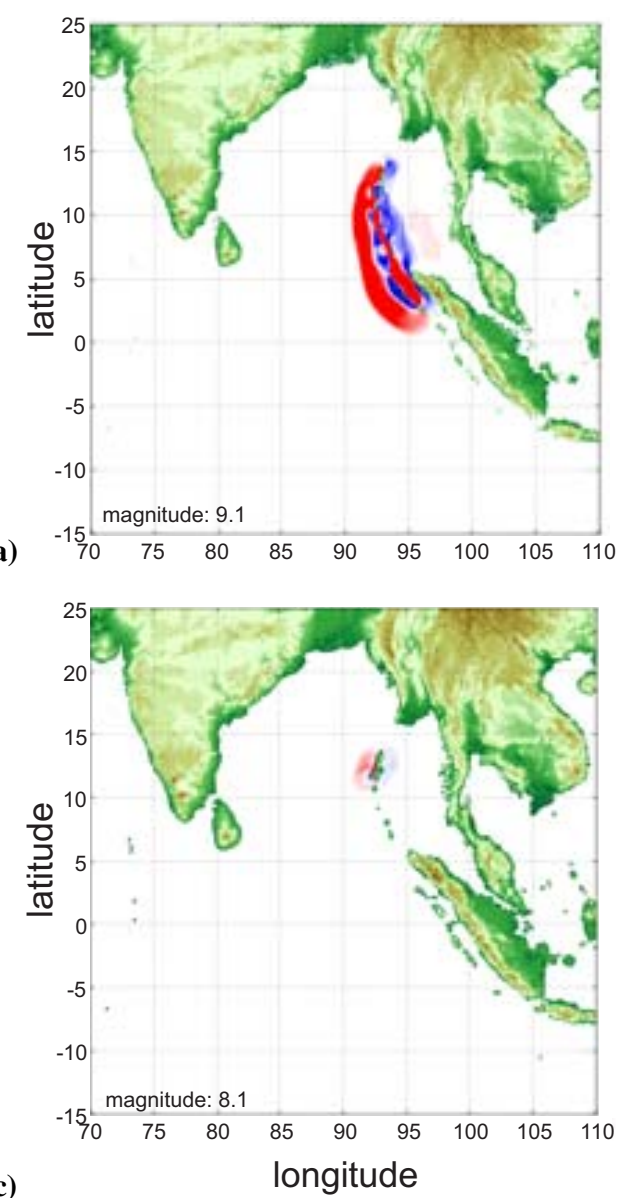

(b)

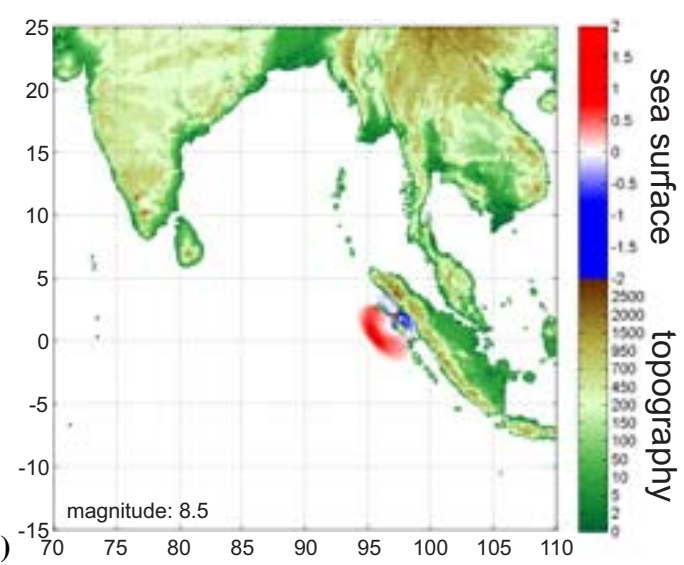

(d)

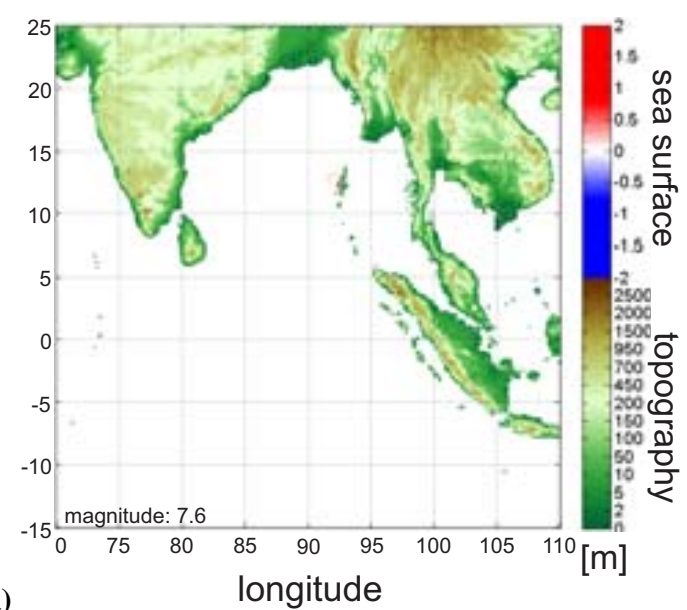

Fig. 5. Tsunami wave propagation simulations of the four strongest historic tsunamis in the Indian Ocean listed in Table 2. The figures show the situation after $15 \mathrm{~min}$. The tsunami events in (c) and (d) are at the same location but modeled with different magnitudes.

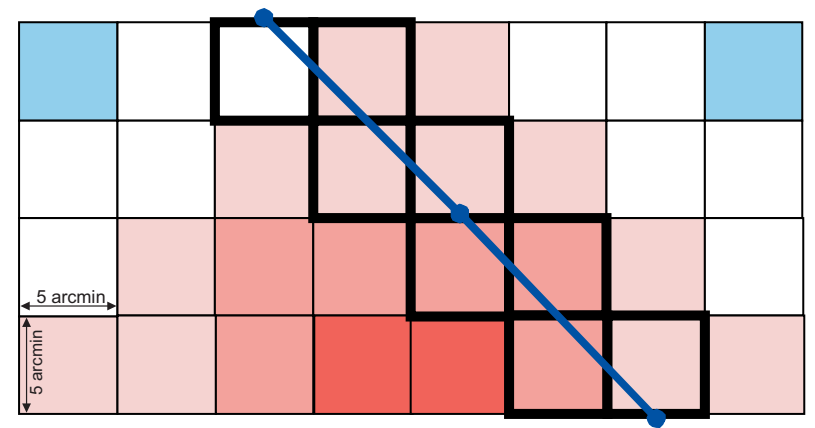

Fig. 6. Schematic representation of a reflection point ground track (line) passing over a tsunami model grid between calculated reflection points (dots). Blue cells show negative, red cells show positive surface height anomalies. Those cells that are crossed by the track are marked bold. These cells are analysed if their absolute height anomaly is higher than the altimetric sensitivity assumed for the GNSS-R system.
2002). Ionospheric delays may be compensated if two signal frequencies can be used. Tropospheric effects are dominated by the water vapor content which is highly variable especially in tropical regions (Heise et al., 2006). The properties of the reflecting surface like roughness or to a lower extent temperature, salinity, polarity and permitivity also may contribute to the overall error (Cardellach, 2001). The reflected signal has to pass the troposphere and ionosphere again until it can be received by the GNSS-R satellite antenna. The signal strength and optical phase path length depend on the gain and the changing orientation of the antenna, respectively (Wu et al., 1993; Beyerle, 2009). Additionally, multipath effects may distort the reflected signal. All of these effects may reduce the altimetric accuracy that can be achieved with such a system. We are aware of these error sources but the complexity of their corrections is beyond the scope of this simulation study. The altimetric sensitivity is therefore a simulation assumption that describes the detectable minimum wave height after an exhaustive elimination of all error sources. In this simulation, tsunami wave anomalies of $20 \mathrm{~cm}$ are assumed, smaller anomalies are considered undetectable. 


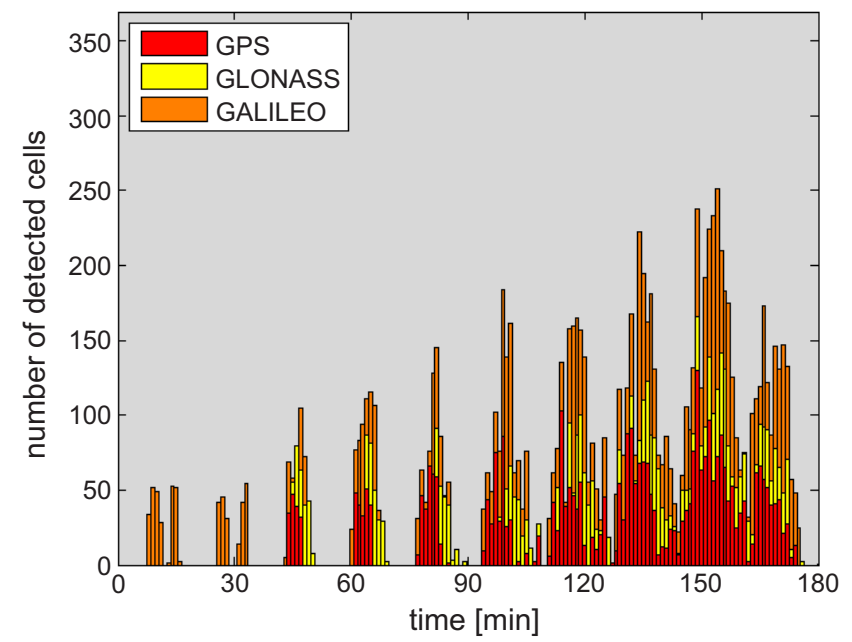

Fig. 7. Detection series for a Sumatra tsunami detection simulation with a LEO GNSS-R 18/3 Walker constellation at $900 \mathrm{~km}$ with $60^{\circ}$ inclination angle and GPS, GLONASS and Galileo as signal sources. The figure shows a periodicity of detections due to the series of LEO satellites along the same orbit passing over the tsunami region. The number of detections increases with time because the tsunami region increases and therefore the probability that a reflection ground track is passing through it. After $150 \mathrm{~min}$ the number of detections decreases because the overall wave height decreases and starts to drop below the assumed altimetric sensitivity limit.

This assumption will be used for the code altimetry as well as for the phase altimetry approach for comparability reasons. We are aware that the altimetric accuracy for phase altimetry from space is still unknown. Each grid cell that will be passed by a reflection point track (Fig. 6) fulfilling this sensitivity criterion will be counted. All cells counted for each time step and within $3 \mathrm{~h}$ after the earthquake represent a tsunami detection series as shown exemplary in Fig. 7.

The moment when a tsunami occurs is a priori unknown and the configurations of the GNSS and LEO satellites are therefore unknown as well. Each detection series calculation is repeated 100 times with random starting times of the tsunami within the same day to account for this randomness. For each time period since the tsunami generation, the number of all simulation runs that show a detection the first time are cumulated. This cumulation of first detections over time forms a step function that can be interpreted in terms of detection probability. The time when this detection probability function reaches $100 \%$ is the maximum time this scenario needs to detect the tsunami with certainty. The detection performance increases with increasing slope of the probability function, i.e. it reaches absolute certainty earlier the higher the performance is.

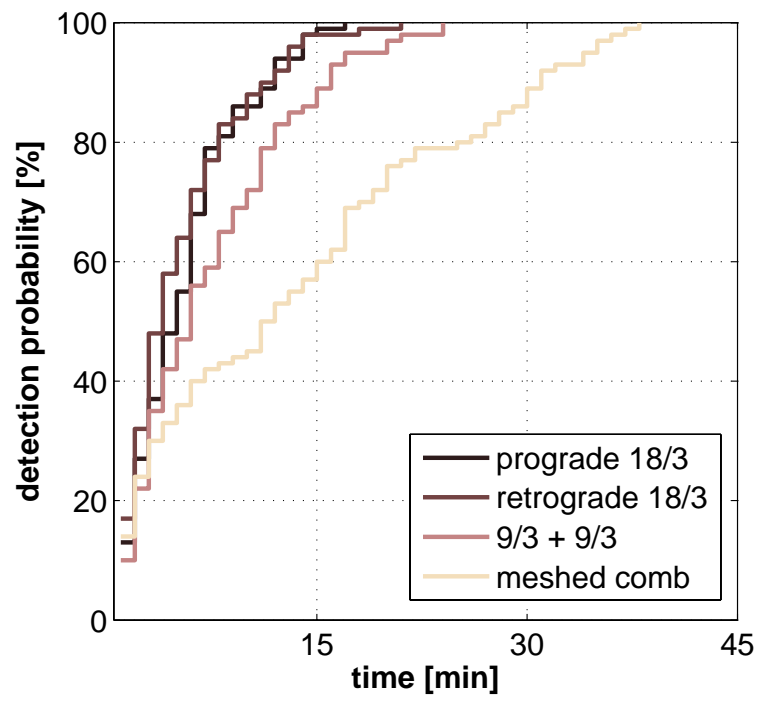

Fig. 8. Tsunami detection probabilities of the same four constellations as in Fig. 3 when applied to the Sumatra tsunami using GPS, GLONASS and Galileo reflections as signal sources.

\section{Detection performance analyses}

In this study we want to investigate which parameters have a significant impact on the detection performance of a LEO GNSS-R-based tsunami detection system. We compare the detection performance of scenarios with different LEO constellations, different tsunamis, different sensitivity assumptions and different orbit parameters. In these analyses the basic simulation assumption of no technical restrictions is retained and the altimetric sensitivity is set to $20 \mathrm{~cm}$. The two different GNSS-R approaches with different antenna concepts mentioned above are also compared. GPS, GLONASS and Galileo together are taken as signal sources assuming they would have been available when the tsunamis occurred in reality. The differences between these GNSS systems with respect to their individual detection performance and their combination is addressed in Stosius et al. (2010).

\subsection{Comparison of different constellation types}

To compare the detection performances of the constellations listed in Table 1, their detection probabilities are calculated for the Sumatra tsunami. Here the combination of GPS, GLONASS and Galileo reflections is considered. The three Walker type constellation scenarios in Fig. 8 show a significantly better detection performance than the meshed comb constellation in Fig. 8 as expected from the reflection point distributions in Fig. 3. The detection performances of the prograde and retrograde 18/3 Walker constellations are very similar and show a certain detection within only 17 and 22 min, respectively. Although the detection probability of the two $9 / 3$ constellations after $15 \mathrm{~min}$ is only $90 \%$, a certain 


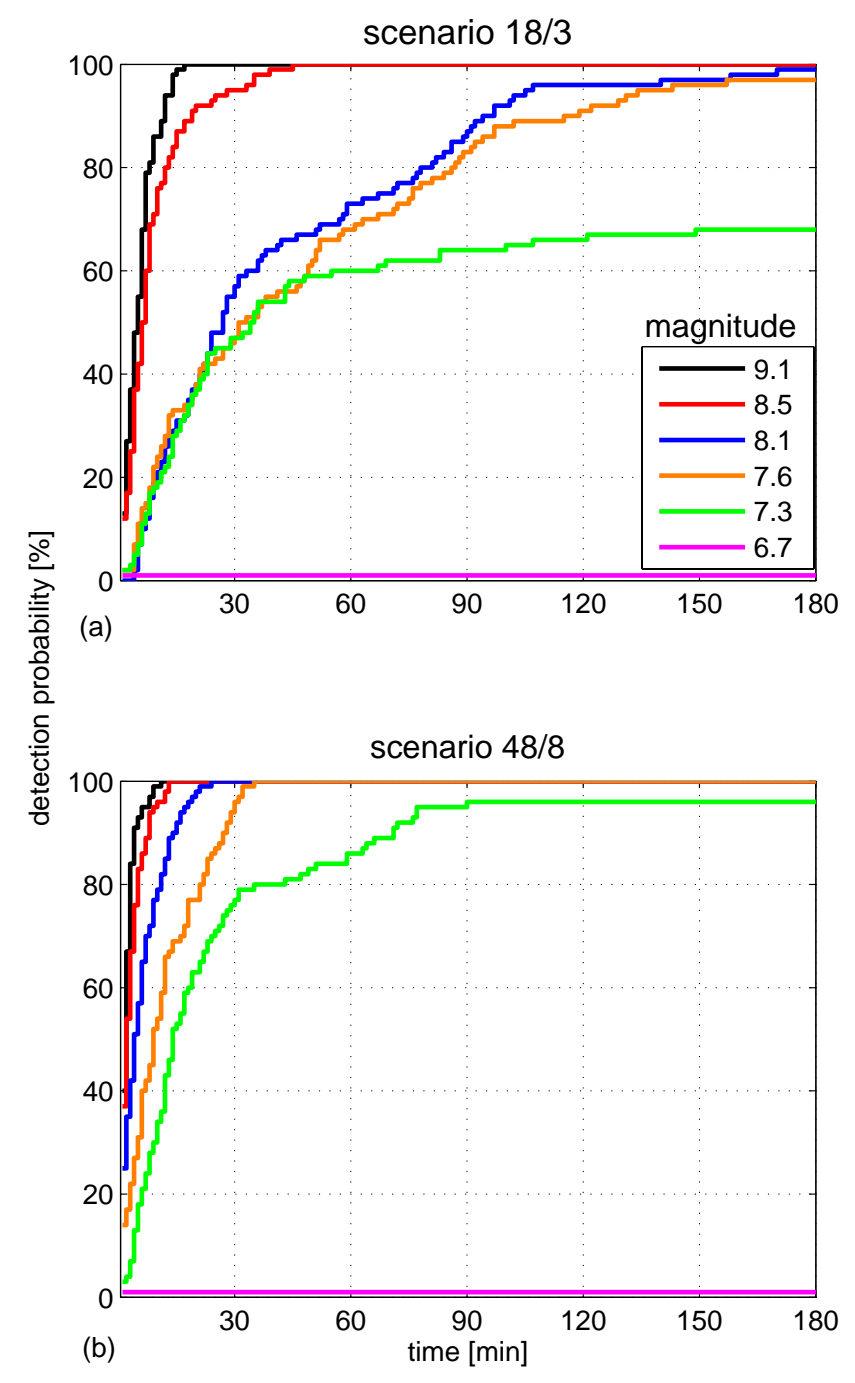

Fig. 9. Detection probability plots for six historical tsunamis in the Indian Ocean (Table 2) triggered by earthquakes with different magnitudes when detected by (a) a 18/3 GNSS-R Walker constellation and (b) a 48/8 GNSS-R Walker constellation at $900 \mathrm{~km}$ with $60^{\circ}$ inclination angle.

detection can be expected within $24 \mathrm{~min}$. For the meshed comb constellation the detection probability is only $60 \%$ after $15 \mathrm{~min}$ and it takes $37 \mathrm{~min}$ for a certain detection. These results confirm that the prograde Walker constellation is best suited for global GNSS-R observations from LEO.

\subsection{Comparison for different tsunamis}

The detection performance for tsunamis with different earthquake magnitudes is compared for six different historical tsunami events (Table 2). The events with $M 8.1$ and 7.6 are the same tsunami but are calculated with different magnitudes found in the literature (Murty and Rafiq, 1991; National Geophysical Data Center, 2009) to investigate the impact of the earthquake magnitude alone.
Figure 9a and b shows detection results for a 18/3 and a $48 / 8$ constellation scenario, respectively. In both cases the detection performance for the 9.1 magnitude event (Sumatra tsunami) is comparable. The detection performance will not increase significantly by having more satellites in the constellation. In the case of the 8.5 magnitude event (Nias tsunami) the performance within the first $15 \mathrm{~min}$ is very high ( $\geq 90 \%$ ) for both scenarios. The probability for the $18 / 3$ scenario reaches $100 \%$ after 45 min while this can be acchieved by the $48 / 8$ scenario within only $12 \mathrm{~min}$, which clearly fulfills a $15 \mathrm{~min}$ detection requirement. The comparison of the medium events with $M 8.1,7.6$, and 7.3 shows a remarkable difference in the detection performance between both scenarios. While all of these events have only about $30 \%$ detection probability after $15 \mathrm{~min}$, in the $18 / 3$ scenario they reach about $90 \%, 70 \%$, and $60 \%$ within the same time for the $48 / 8$ scenario, respectively. The 8.1 and 7.6 events differ only in magnitude but not in location. The 8.1 event will be detected with certainty nearly after the same time as the 7.6 event when taking the $18 / 3$ scenario. For the $48 / 8$ scenario the certain detection of the 8.1 event will be reached $\sim 10$ min earlier than that of the 7.6 event. During the last 10 decades the tsunami events in Indonesia that have taken the lives of more than 100 people were triggered by earthquakes with $M \geq 7.7$ (National Geophysical Data Center, 2009). The simulations show that a 7.6 event can be detected within 35 min with certainty when using the $48 / 8$ constellation, but this cannot be guaranteed with only a $18 / 3$ constellation. An event with $M 6.7$ is too small in size and wave height and cannot be detected by any of these constellations, but such events are not really perilous.

\subsection{Comparison of different orbit parameters}

The orbit parameters "altitude" and "inclination angle" of the GNSS-R Walker constellations used in this study are varied to show their impact on the detection performance. The orbit altitudes chosen are $450 \mathrm{~km}, 600 \mathrm{~km}, 800 \mathrm{~km}, 1350 \mathrm{~km}$, and $1800 \mathrm{~km}$ and the orbit inclinations vary between $40^{\circ}$ and $80^{\circ}$ with an increment of $10^{\circ}$. In addition, the number of satellites and the number of orbit planes are varied to create the six different constellation scenarios listed in Table 3 . The combination of all parameters adds to 180 different scenarios. For each parameter combination, the detection performance analysis is carried out for the most devastating Sumatra and Nias tsunami, respectively. The detection time is crucial for early warning, and the shorter this time is, the more effective the early warning can be. The detection time is therefore classified by 15 min time intervals. For each calculation the time when the detection probability reaches $100 \%$ is sorted into one of the detection time classes $1: \leq 15 \mathrm{~min}$, $2: \leq 30 \mathrm{~min}, 3: \leq 45 \mathrm{~min}$ or $4:>45 \mathrm{~min}$ or not at all. The classified results for each parameter combination of each scenario are shown in Fig. 10 for the Sumatra and Nias tsunami, respectively. 


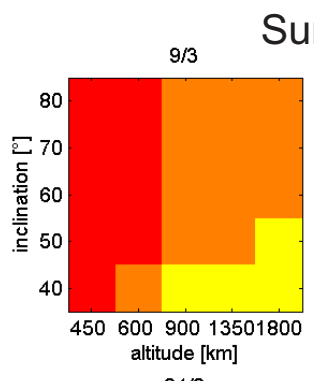

$24 / 8$

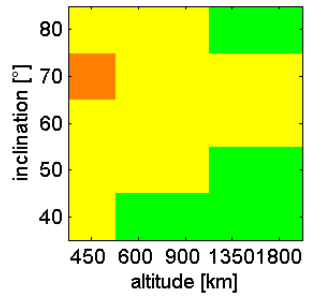

$48 / 8$

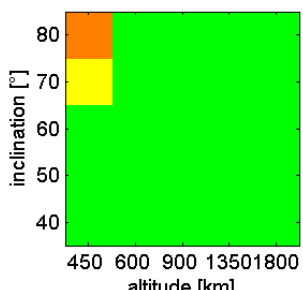

altitude $[\mathrm{km}]$
Sumatra

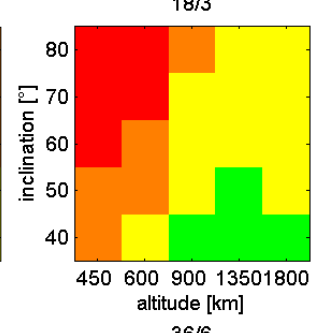

$36 / 6$

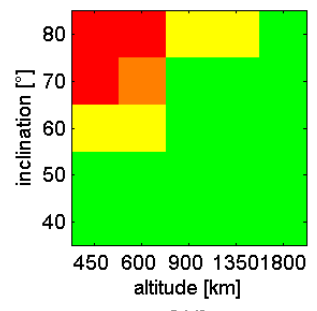

$81 / 9$

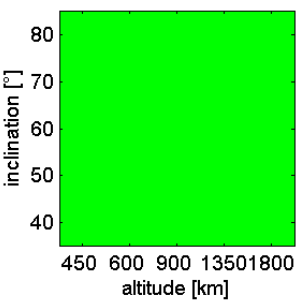

Nias

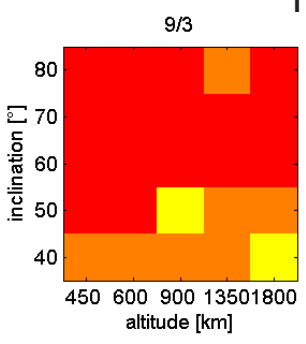

$24 / 8$

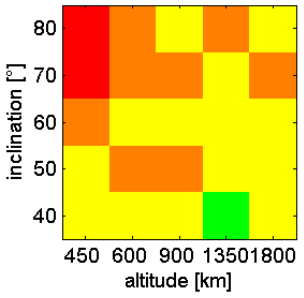

$48 / 8$

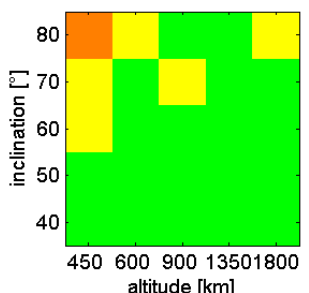

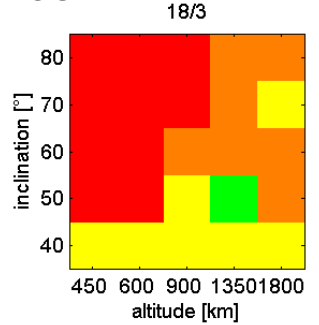

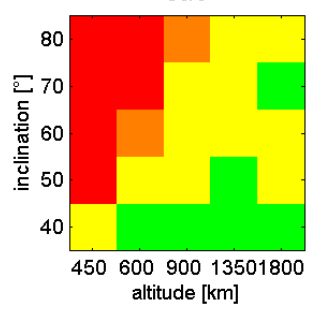

$81 / 9$

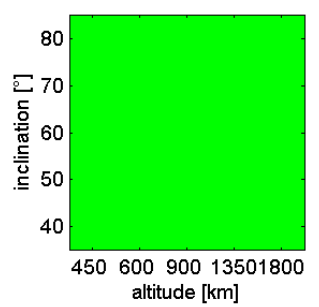

Fig. 10. Maximum detection times of six GNSS-R Walker constellation scenarios (Table 3) for all combinations of orbit altitude and inclination angle when applied to the Sumatra tsunami (left) and the Nias tsunami (right) with $20 \mathrm{~cm}$ altimetric sensitivity assumption. Green boxes indicate a certain detection of the tsunami within $15 \mathrm{~min}$ after the earthquake, yellow indicates detection within 30 min, orange within $45 \mathrm{~min}$ and red beyond $45 \mathrm{~min}$ or no detection at all.

In general, the detection time decreases with the total number of satellites of the scenario. The detection time is higher for lower orbit altitudes. This is obvious because the field of view and, therefore, the number of visible reflection ground tracks increases with orbit altitude. The detection time decreases with an increase of orbit inclination because the tsunamis observed here are close to the Equator and there the number of repeated observations increases when the orbit inclination is low. This may be different for tsunamis at higher latitudes which has not been investigated here. The classification of detection times in Fig. 10 shows clearly, that a $9 / 3$ constellation is inappropriate for tsunami detection at all and also the 18/3 scenario only shows good results for low inclinations and high orbit altitudes. Although the results for the 24/8 and 36/6 scenarios look promising for the Sumatra event this can not be stated for the Nias event. The $36 / 6$ detection result for the Nias event looks very similar to the $18 / 3$ result of the Sumatra event, which means that the number of satellites and orbit planes must be doubled to achieve similar detection results for the Nias tsunami. With a $48 / 8$ constellation nearly the same detection results can be expected for both events and with the 81/9 scenario a certain detection within $15 \mathrm{~min}$ can be achieved for both events for all altitude and inclination combinations.
Table 3. Number of satellites and orbit planes for six GNSS-R Walker constellation scenarios.

\begin{tabular}{lcccccc}
\hline num. of satellites & 9 & 18 & 24 & 36 & 48 & 81 \\
$\begin{array}{l}\text { num. of orbit } \\
\text { planes }\end{array}$ & 3 & 3 & 8 & 6 & 8 & 9 \\
$\begin{array}{l}\text { num. of satellites } \\
\text { per orbit plane } \\
\text { designator }\end{array}$ & 3 & 6 & 3 & 6 & 6 & 9 \\
\hline
\end{tabular}

\subsection{Comparison of different altimetric sensitivity assumptions}

To analyse the performance of the tsunami detection with respect to the altimetric sensitivity, different assumptions are made. In Fig. 11 the detection probability of the 18/3 and the $48 / 8$ scenario is calculated for the four strongest tsunamis in Table 2. The altimetric sensitivity is varied between $10 \mathrm{~cm}, 20 \mathrm{~cm}, 50 \mathrm{~cm}$, and $100 \mathrm{~cm}$. In the case of the Sumatra tsunami (Fig. 11a and e) in both scenarios no significant difference between the results of all four sensitivities 


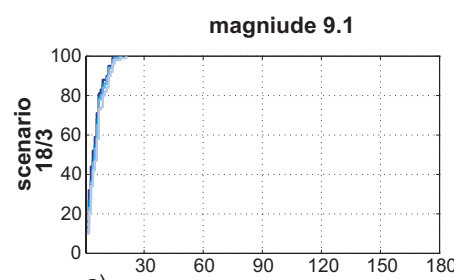

a)

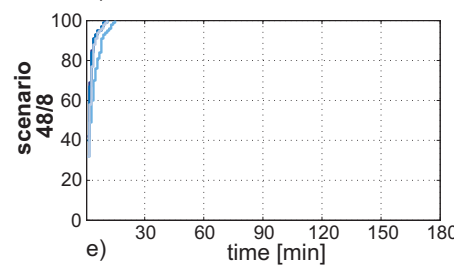

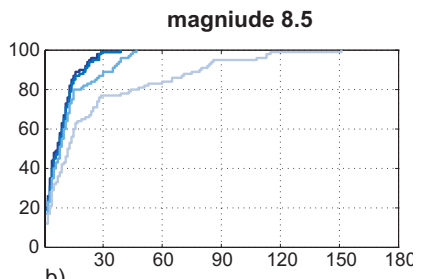

b)

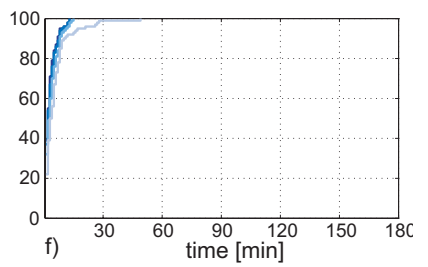

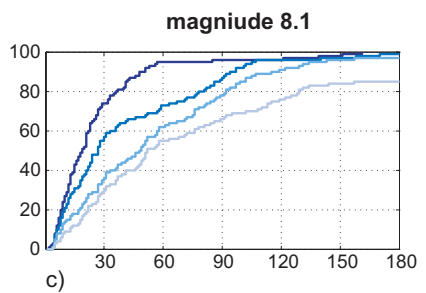

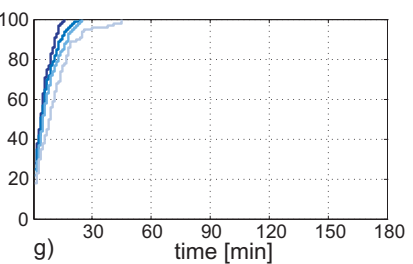

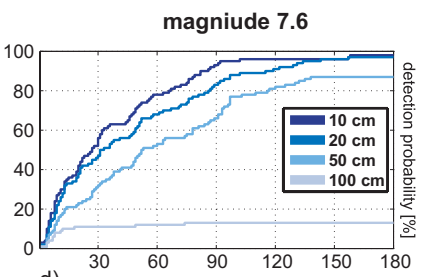

d)

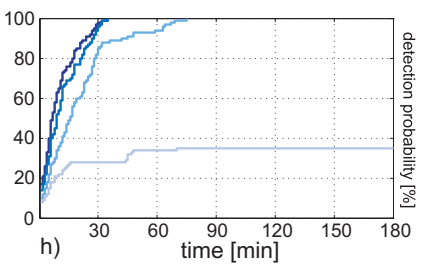

Fig. 11. Tsunami detection probability functions for the scenarios $18 / 3$ in the upper row and $48 / 8$ in the lower row, all with $60^{\circ}$ inclination angle, $900 \mathrm{~km}$ altitude, and applied to four tsunami events with earthquake $M 9.1,8.5,8.1$, and 7.6 (Table 2). Altimetric sensitivity assumptions are varied between $10 \mathrm{~cm}, 20 \mathrm{~cm}, 50 \mathrm{~cm}$, and $100 \mathrm{~cm}$.

can be found, because the detectable tsunami wave heights of this event are $\geq 100 \mathrm{~cm}$ within the first 20 min after the earthquake. For the 18/3 scenario of the Nias event (Fig. 11b) the results for a sensitivity of $10 \mathrm{~cm}, 20 \mathrm{~cm}$, and $50 \mathrm{~cm}$ are similar within the first $15 \mathrm{~min}$. After that the $50 \mathrm{~cm}$ probability function starts to differ slightly from that of the 10 and $20 \mathrm{~cm}$ sensitivity. The detection performance of the $100 \mathrm{~cm}$ sensitivity is significantly lower. It reaches only $60 \%$ after $15 \mathrm{~min}$ and $100 \%$ only after $151 \mathrm{~min}$. This can not be observed in the 48/8 scenario of the Nias event (Fig. 11f). The detection probability stays below the $15 \mathrm{~min}$ requirement for the 10,20 , and $50 \mathrm{~cm}$ sensitivity and is very high $(\sim 90 \%)$ for the $100 \mathrm{~cm}$ sensitivity. The tsunami event of 1941, which is calculated for both scenarios with $M 8.1$ (Fig. 11c and g) and with $M 7.6$ (Fig. 11d and h) shows significant differences in the detection performance between the four sensititvity assumptions. For both scenarios the probabilities start to diverge after 5 to $10 \mathrm{~min}$. In the $18 / 3$ scenario $100 \%$ detection probability is not reached within the $3 \mathrm{~h}$ period after the earthquake with any of the sensitivity assumptions. With the $10 \mathrm{~cm}$ sensitivity only $40 \%$ and $30 \%$ can be reached within $15 \mathrm{~min}$ in the 8.1 and 7.6 magnitude event, respectively. The performance difference between $10 \mathrm{~cm}$ and $100 \mathrm{~cm}$ sensitivity is up to $\sim 40 \%$ for the 8.1 event and up to $85 \%$ for the 7.6 event. In the case of the $48 / 8$ scenario the detection performance for the 8.1 event (Fig. $11 \mathrm{~g}$ ) is very high. The tsunami would be detected within $15 \mathrm{~min}$ for the $10 \mathrm{~cm}$ sensitivity and $45 \mathrm{~min}$ for the $100 \mathrm{~cm}$ sensitivity, respectively. For the 7.6 event (Fig. 11h) the detection performance of the 10 and $20 \mathrm{~cm}$ sensitivity is still good but for the $50 \mathrm{~cm}$ sensitivity the certain detection takes up to $75 \mathrm{~min}$. The $100 \mathrm{~cm}$ sensitivity will not reach more than $35 \%$ which is not sufficient for tsunami detection at all because this means that only about 1 of 3 tsunamis is detectable. The overall result of this analysis is that at least a $48 / 8$ scenario is necessary to fulfill the $15 \mathrm{~min}$ requirement for the detection of a strong or medium tsunami and that the altimetric sensitivity should be at least $20 \mathrm{~cm}$ to detect a tsunami with $M \geq 7.6$.

\subsection{Comparison of different GNSS-R altimetry approaches}

The PARIS (Martín-Neira, 1993) or code altimetry approach uses GNSS signals that are scattered due to the roughness of the reflecting surface. It requires an uplooking right handed circular polarized (RHCP) antenna for the direct GNSS signals and a downlooking left handed circular polarized (LHCP) antenna to retrieve the reflections. The signalto-noise ratio (SNR) of scattered GNSS signals is very low and the antenna gain must therefore be very high $(\sim 23 \mathrm{~dB}$ (Martín-Neira et al., 2008)). To retrieve several scattered reflections from different directions simultaneously, a high gain antenna with beam steering is necessary, which is technically challenging. From bistatic model theory, e.g. (Valenzuela, 1978; Voronovich, 1994), it is known that for reflections on sea surfaces at small elevation angles below $\sim 20^{\circ}-30^{\circ}$, effects like trapping or Bragg scattering start to dominate the scattering process. In this case the SNR becomes very low, so that this approach is, therefore, applicable only for reflections with higher elevation angles.

In carrier phase altimetry the interference between direct signals and coherent reflections are used to determine the height or height variation of the reflecting surface. Coherent reflections can only be observed at low elevation angles with low gain (10-20 dB) RHCP antennas (Beyerle and Hocke, 2001) directing to horizon. This antenna configuration is applied in radio occultation experiments like on CHAMP, GRACE or COSMIC/Formosat-3 (Wickert et al., 2009). In these satellite missions one or two antennas looking in aft and/or forward direction are used. 

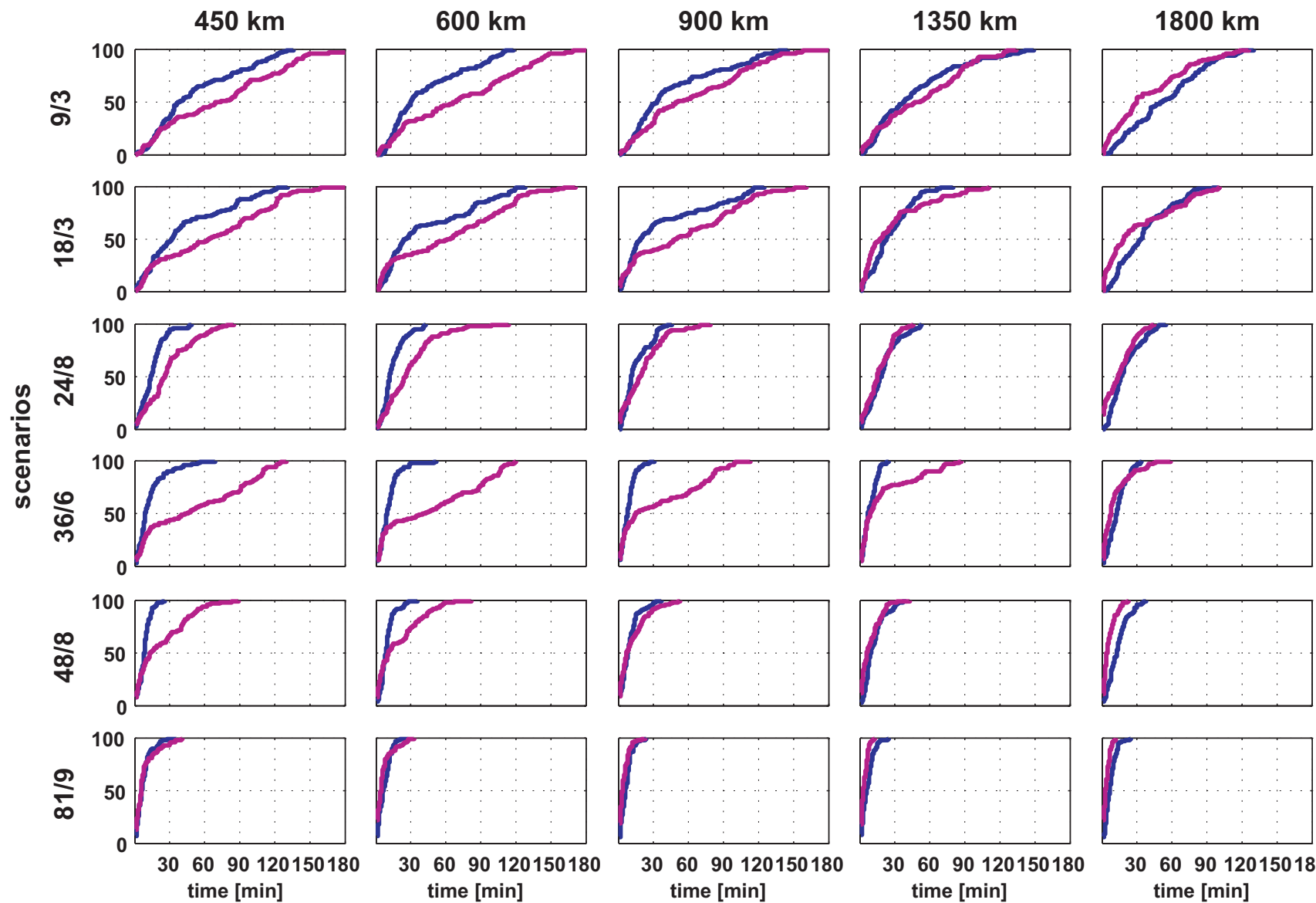

306090120150180 time [min]

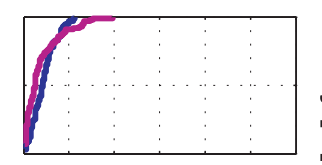

orbit height
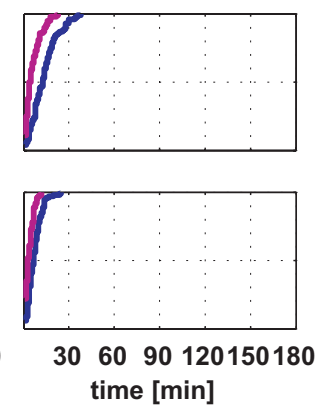

phase altimetry

PARIS

Fig. 12. Sumatra tsunami detection probability plots for six different constellation scenarios with five different orbit altitudes, all at $60^{\circ}$ inclination angle. GPS, GLONASS and Galileo are taken as signal sources and the altimetric sensitivity is assumed to be $20 \mathrm{~cm}$. The plots show results for a carrier phase altimetry antenna configuration (fore and aft looking, $120^{\circ}$ full opening angle, elevations $<10^{\circ}$ ) in blue and for a PARIS configuration (downlooking omnidirectional antenna, elevations $>30^{\circ}$ ) in magenta.

To compare these two approaches, the detection simulation is repeated for two different antenna configuration scenarios. The PARIS approach is applied with a downlooking omnidirectional antenna assuming that the antenna can be steered to all directions from where reflections can be retrieved. The elevation angle of receivable signals is restricted to $\geq 30^{\circ}$. For the carrier phase approach a typical radio occultation configuration with a fore and an aft looking antenna with $120^{\circ}$ opening angle is chosen. This configuration is recommended in a phase A study of the planned MicroGEM satellite. This micro satellite is designed for radio occultation, carrier phase reflectometry and gravimetry using precise orbit determination (POD), satellite laser ranging (SLR) and very-long baseline interferometry (VLBI) in combination (Brieß et al., 2009). In this simulation the elevation angle for this approach is restricted to $<10^{\circ}$.
Figure 12 shows the detection probability plots for both GNSS-R altimetry approaches when applied to the Sumatra tsunami. Different LEO GNSS-R Walker constellations at different orbit altitudes with $60^{\circ}$ inclination angle are included. As stated above the detection performance increases with the number of satellites in the constellation and with orbit altitude for both approaches. Regarding the first $15 \mathrm{~min}$ after the earthquake both approaches perform very similar. For orbit altitudes up to $900 \mathrm{~km}$ and the scenarios with up to 48 satellites the phase altimetry probability functions are steeper than the PARIS functions, which indicates that in these cases the detection performance is better because the tsunami will be detected earlier with a higher degree of certainty. At higher orbits or with a higher number of satellites both approaches perform similar and in some cases the PARIS approach performs slightly better. Consequently 
both concepts perform similar at high orbits. At low orbits the phase altimetry approach should be preferred. Only the PARIS concept results for the $81 / 9$ scenario with $\geq 1350 \mathrm{~km}$ altitude stay below the $15 \mathrm{~min}$ detection time requirement. Despite of this exception none of these two concepts is able to fulfill the $15 \mathrm{~min}$ requirement alone, and because of that a GNSS-R tsunami detection system should combine both approaches.

\section{Conclusions}

A tsunami detection simulation study has been carried out with GNSS-R as detection system that is able to measure sea surface height anomalies induced by tsunamis. As the Sumatra tsunami has shown, a limit of 15 min detection time is required for such a tsunami detection system. In this study GPS, GLONASS and Galileo signals are assumed to be available and GNSS-R receivers are applicable aboard LEO satellites in a constellation. In a first step a meshed comb and several types of Walker constellations are compared with respect to their global reflection point distribution. It can be shown that the Walker constellations outperform the meshed comb constellation. The simulations consider prograde Walker constellations as most appropriate for global GNSS-R tsunami detection. The detection performance is calculated based on first time detections of 100 independent detection series. The detection performance for several parameter combinations is analysed. The parameters taken into account are orbit altitude, inclination angle, number of satellites and number of orbit planes of the GNSS-R LEO constellation as well as the altimetric sensitivity and the GNSS-R altimetry approach. Tsunami wave heights are modeled for six historical tsunamis in the Indian Ocean. The analyses show that very strong tsunamis can be detected within $15 \mathrm{~min}$ with 18 LEO satellites only at special orbit parameter combinations and weaker tsunami events can not be detected adequately even with 48 satellites. The detection performance in general increases with the number of satellites and the orbit altitude. For tsunamis in the Indian Ocean low inclination angles are advantageous but a global detection system should operate at least up to $60^{\circ}$ latitude. With a $48 / 8$ constellation and at least $20 \mathrm{~cm}$ altimetric sensitivity strong and medium tsunamis can be detected within 15 to $25 \mathrm{~min}$. These results only hold true under the assumption that all reflections that occur geometrically are receivable technically and that errors can be reduced to obtain an altimetric sensitivity adequate for tsunami detection. In reality there are many principal and technical drawbacks. Two different GNSS-R altimetry approaches with different antenna configurations exist. The simulations show that the carrier phase approach outperforms the PARIS or code altimetry approach especially at low orbit altitudes and for a low number of LEO satellites. Both approaches alone do not fulfill the $15 \mathrm{~min}$ requirement and, therefore, any GNSS-R tsunami detection system should combine both approaches to build an effective operational tsunami detection system. In addition there must be an efficient downlink concept to transmit the data immediately. This requires some kind of on board processing, a network of downlink stations (ideally located near vulnerable coastal regions) and/or a communication satellite network as well as a tsunami early warning center to evaluate the data and to mitigate the warning. A GNSS-R system like the one proposed here would not be designed only for tsunami detection alone but for GNSS-R observations of water, ice and land as well as for atmospheric sounding, i.e. radio occultation. This can be achieved with similar or the same GNSS-R hardware, which makes GNSS-R a very versatile remote sensing technique.

Acknowledgements. The GITEWS project (German Indonesian Tsunami Early Warning System) is carried out through a large group of scientists and engineers from (GFZ) German Research Centre for Geosciences and its partners from the German Aerospace Centre (DLR), the Alfred Wegener Institute for Polar and Marine Research (AWI), the GKSS Research Centre, the Konsortium Deutsche Meeresforschung (KDM), the Leibniz Institute for Marine Sciences (IFM-GEOMAR), the United Nations University (UNU), the Federal Institute for Geosciences and Natural Resources (BGR), the German Agency for Technical Cooperation (GTZ), as well as from Indonesian and other international partners. This is publication number 110 . Funding is provided by the German Federal Ministry for Education and Research (BMBF), Grant 03TSU01.

Edited by: J. Lauterjung

Reviewed by: two anonymous referees

\section{References}

Ablain, M., Dorandeu, J., Le Traon, P.-Y., and Sladen, A.: The Indian Ocean Tsunami of December 26, 2004, Observed by High Resolution Altimetry, in: 15 Years of Progress in Radar Altimetry Symposium, Venice, Italy, 2006.

Anthes, R. A., Bernhardt, R. A., Chen, Y., Cucurull, L., Dymond, K. F., Ector, D., Healy, S. B., Ho, S.-P., Hunt, D. C., Kuo, Y.H., Liu, H., Manning, K., Mccormick, C., Meehan, T. K., Randel, W. J., Rocken, C., Schreiner, W. S., Sokolovskiy, S. V., Syndergaard, S., Thompson, D. C., Trenberth, K. E., Wee, T.K., Yen, N. L., and Zhang, Z.: The COSMIC/FORMOSAT-3 Mission - Early Results, B. Am. Math. Soc., 89, 313-333, doi: 10.1175/BAMS-89-3-313, 2008.

Babeyko, A. Y., Hoechner, A., and Sobolev, S. V.: Source Modeling and Inversion with Real-Time GPS: a GITEWS Perspective for Indonesia, Nat. Hazard Earth Sys., in review, 2010.

Behrens, J., Androsov, A., Babeyko, A. Y., Harig, S., Klaschka, F., and Mentrup, L.: A new multi-sensor approach to simulation assisted tsunami early warning, Nat. Hazards Earth Syst. Sci., 10, 1085-1100, doi:10.5194/nhess-10-1085-2010, 2010.

Beyerle, G.: Carrier Phase Wind-Up in GPS Reflectometry, GPS Solut., 13, 191-198, doi:10.1007/s10291-008-0112-1, 2009.

Beyerle, G. and Hocke, K.: Observation and Simulation of Direct and Reflected GPS Signals in Radio Occultation Experiments, Geophys. Res. Lett., 28, 1895-1898, 2001. 
Beyerle, G., Hocke, K., Wickert, J., Schmidt, T., Marquardt, C., and Reigber, C.: GPS Radio Occultations with CHAMP: A Radio Holographic Analysis of GPS Signal Propagation in the Troposphere and Surface Reflections, J. Geophys. Res., 107, 48024815, doi:10.1029/2001JD001402, 2002.

Brieß, K., Kornemann, G., and Wickert, J.: MicroGEM - Microsatellites for GNSS Earth Monitoring, Abschlussbericht Phase 0/A, Helmholtz-Zentrum Potsdam Deutsches GeoForschungsZentum GFZ und Technische Universität Berlin, 2009.

Brune, S., Babeyko, A. Y., and Sobolev, S. V.: Are Tilt Measurements Useful in Detecting Tsunamigenic Submarine Landslides?, Geochem. Geophy. Geosy., 10, 1-12, doi:10.1029/ 2009GC002491, 2009.

Brune, S., Babeyko, A. Y., Ladage, S., and Sobolev, S. V.: Landslide tsunami hazard in the Indonesian Sunda Arc, Nat. Hazards Earth Syst. Sci., 10, 589-604, doi:10.5194/nhess-10-589-2010, 2010.

Cardellach, E.: Sea Surface Determination Using GNSS Reflected Signals, Ph.D. thesis, Universitat Politècnica de Catalunya (UPC), Barcelona, 2001.

Cardellach, E., Ruffini, G., Pino, D., Rius, A., Komjathy, A., and Garrison, J. L.: MEditerranean Balloon EXperiment: Ocean Wind Speed Sensing from the Stratosphere, Using GPS Reflections, Remote Sens. Environ., 88, 351-362, 2003.

Cardellach, E., Ao, C. O., de la Torre Juárez, M., and Hajj, G. A.: Carrier Phase Delay Altimetry with GPS-Reflection/Occultation Interferometry from Low Earth Orbiters, Geophys. Res. Lett., 31, $1-4,2004$.

Cardellach, E., Fabra, F., Nogués-Correig, O., Oliveras, S., Ribó, S., Rius, A., and Belmonte-Rivas, M.: From Greenland to Antarctica: CSIC/IEEC Results on Sea-Ice, Dry-Snow, Soil-Moisture and Ocean GNSS Reflections, in: 2nd International Colloquium - Scientific and Fundamental Aspects of the GALILEO Programme, COSPAR Colloquium, Padua, Italy, 14-16 October 2009.

Dow, J. M., Neilan, R. E., and Gendt, G.: The International GPS Service: Celebrating the 10th Anniversary and Looking to the Next Decade, Adv. Space Res., 36, 320-326, doi:10.1016/j.asr. 2005.05.125, 2005.

Falck, C., Ramatschi, M., Subarya, C., Bartsch, M., Merx, A., Hoeberechts, J., and Schmidt, G.: Near real-time GPS applications for tsunami early warning systems, Nat. Hazards Earth Syst. Sci., 10, 181-189, doi:10.5194/nhess-10-181-2010, 2010.

Garrison, J. L. and Katzberg, S. J.: The Application of Reflected GPS Signals to Ocean Remote Sensing, Remote Sens. Environ., 73, 175-187, 2000.

Garrison, J. L., Katzberg, S. J., and Howell III, C. T.: Detection of Ocean Reflected GPS Signals: Theory and Experiment, in: Proceedings of the IEEE Southeastcon '97: Engineering the New Century, Blacksburg, VA, 12-14 April 1997, 290-294, doi:10. 1109/SECON.1997.598694, 1997.

Garrison, J. L., Katzberg, S. J., and Hill, M. I.: Effect of Sea Roughness on Bistatically Scattered Range Coded Signals from the Global Positioning System, Geophys. Res. Lett., 25, 2257-2260, 1998.

Garrison, J. L., Komjathy, A., Zavorotny, V. U., and Katzberg, S. J.: Wind Speed Measurement Using Forward Scattered GPS Signals, IEEE T. Geosci. Remote, 40, 50-65, 2002.
Germain, O. and Ruffini, G.: A Revisit to the GNSS-R Code Range Precision, in: Proceedings of the GNSS-R'06 Workshop, ESTEC, Noordwijk, The Netherlands, 14-15 June 2006.

Gleason, S., Hodgart, S., Sun, Y., Gommenginger, C., Mackin, S., Adjrad, M., and Unwin, M.: Detection and Processing of Bistatically Reflected GPS Signals from Low Earth Orbit for the Purpose of Ocean Remote Sensing, IEEE T. Geosci. Remote, 43, 1229-1241, 2005.

Gorbunov, M.: Ionospheric Correction and Statistical Optimization of Radio Occultation Data, Radio Sci., 37(5), 1084, doi:10.1029/2000RS002370, 2002.

Hajj, G. A., Ao, C. O., Iijima, B. A., Kuang, D., Kursinski, E. R., Mannucci, A. J., Meehan, T. K., Romans, L. J., de la Torre Juárez, M., and Yunck, T. P.: CHAMP and SAC-C Atmospheric Occultation Results and Intercomparisons, J. Geophys. Res., 109, D06109, doi:10.1029/2003JD003909, 2004.

Hanka, W., Saul, J., Weber, B., Becker, J., and GITEWS team: Timely regional tsunami warning and rapid global earthquake monitoring, Orfeus Newsletter, 8(1), available at: http://www.orfeus-eu.org/Organization/Newsletter/vol8no1/ onl_seiscomp/onl_seiscomp.htm (last access: June 2010), 2008.

Heise, S., Wickert, J., Beyerle, G., Schmidt, T., and Reigber, C.: Global Monitoring of Tropospheric Water Vapor with GPS Radio Occultation Aboard CHAMP, Adv. Space Res., 37(12), 2222 2227, doi:10.1016/j.asr.2005.06.066, 2006.

Helm, A., Stosius, R., Beyerle, G., Montenbruck, O., and Rothacher, M.: Status of GNSS Reflectometry Related Receiver Developments and Feasibility Studies within the German Indonesian Tsunami Early Warning System, in: IGARSS 2007, Barcelona, Spain, 23-28 July, IEEE International, 5084-5087, doi:10.1109/IGARSS.2007.4424005, 2008.

Hoechner, A., Babeyko, A. Y., and Sobolev, S. V.: Enhanced GPS Inversion Technique Applied to the 2004 Sumatra Earthquake and Tsunami, Geophys. Res. Lett., 35, L08310, doi:10.1029/2007GL033133, 2008.

Hoots, F. R. and Roehrich, R. L.: Model for Propagation of NORAD Element Sets, U.S. Air Force Aerospace Defense Command, Colorado Springs, CO, Spacetrack Report No. 3, 91 pp., 1980 .

Imamura, F., Goto, C., Ogawa, Y., and Shuto, N.: IUGG/IOC Time Project - Numerical method of tsunami simulation with the leapfrog scheme, UNESCO, IOC Manuals and Guides No. 35, 1997.

ITIC (International Tsunami Information Centre): Tsunami Newsletter, XXXXVII(2), 28 pp., 2005.

Jackson, B.: Performance of Meshed Comb Constellations for Minimizing Target Revisit Time, in: IEEE Aerospace Conference, Snowmass at Aspen, CO, USA, 21-28 March, 5, 59-69, doi: 10.1109/AERO.1998.685792, 1998.

Kanamori, H.: Seismological Aspects of the December 2004 Great Sumatra-Andaman Earthquake, Earthq. Spectra, 22, 1-12, 2006

Larson, W. J. and Wertz, J. R. (Eds.): Space Mission Analysis and Design, 2nd edn., Space Technology Series, Microcosm, Inc. \& Kluwer Academic Press, 1995.

Lowe, S. T., LaBrecque, J. L., Zuffada, C., Romans, L. J., Young, L. E., and Hajj, G. A.: First Spaceborne Observation of an Earthreflected GPS Signal, Radio Sci., 37, 1007-1035, doi:10.1029/ 2000RS002539, 2002.

Martín-Neira, M.: A Passive Reflectometry and Interferometry System (PARIS): Application to Ocean Altimetry, Radio-Frequency 
Division, ESTEC, Noordwijk, The Netherlands, ESA J.-Eur. Space Agen., 17, 331-355, 1993.

Martín-Neira, M., Colmenarejo, P., Ruffini, G., and Serra, C.: Altimetry Precision of $1 \mathrm{~cm}$ over a Pond Using the Wide-Lane Carrier Phase of GPS Reflected Signals, Can. J. Remote Sens., 28, 394-403, 2002.

Martín-Neira, M., Buck, C., Gleason, S., Unwin, M., Caparrini, M., Farrés, E., Germain, O., Ruffini, G., and Soulat, F.: Tsunami Detection Using the PARIS Concept, in: Progress in Electromagnetics Research Symposium 2005, Hangzhou, China, 22-26 August 2005.

Martín-Neira, M., D’Addio, S., and Buck, C.: PARIS In-Orbit Demonstrator, in: PARIS IOD Meeting, CDTI, Madrid, Spain, 20 October 2008.

Murty, T. S. and Rafiq, M.: Research Note: A Tentative List of Tsunamis of the North Indian Ocean in the Marginal Seas, Nat. Hazards, 4, 81-83, 1991.

National Geophysical Data Center: NOAA/WDC Historical Tsunami Database at NGDC, National Oceanic and Atmospheric Administration (NOAA), available at: http://www.ngdc.noaa. gov/hazard/tsu_db.shtml (last access: 28 November 2009), 2009.

NAVSTAR: Global Positioning System Standard Positioning Service Signal Specification, 2nd edn., Tech. rep., 1995.

NOAA/IOC/ITIC/LDG: Tsunami - The Great Waves, available at: http://www.erh.noaa.gov/er/akq/tsunami_brochure.pdf (last access: 3 May 2008), 2002.

Nogués-Correig, O., Cardellach Gali, E., Sanz Campderros, J., and Rius, A.: A GPS-Reflections Receiver that Computes Doppler/Delay Maps in Real-Time, IEEE T. Geosci. Remote, 45, 156-174, doi:10.1109/TGRS.2006.882257, 2007.

Pavelyev, A. G., Volkov, A. V., Zakharov, A. I., Krutikh, S. A., and Kucherjavenkov, A. I.: Bistatic Radar as a Tool for Earth Investigation Using Small Satellites, Acta Astronaut., 39, 721730, 1996.

Rius, A., Aparicio, J. M., Cardellach, E., Martín-Neira, M., and Chapron, B.: Sea Surface State Measured Using GPS Reflected Signals, Geophys. Res. Lett., 29, 2122-2125, doi:10. 1029/2002GL015524, 2002.

Rudloff, A., Lauterjung, J., Münch, U., and Tinti, S.: Preface "The GITEWS Project (German-Indonesian Tsunami Early Warning System)", Nat. Hazards Earth Syst. Sci., 9, 1381-1382, doi:10.5194/nhess-9-1381-2009, 2009.
Ruffini, G., Soulat, F., Capparrini, M., and Germain, O.: The GNSS-R Eddy Experiment I: Altimetry from Low Altitude Aircraft, in: Proceeding from the 2003 Workshop on Oceanography with GNSS Reflections, Barcelona, Spain, 2004.

Sobolev, S. V., Babeyko, A. Y., Wang, R., Hoechner, A., Galas, R., Rothacher, M., Sein, D. V., Schröter, J., Lauterjung, J., and C., S.: Tsunami Early Warning Using GPS-Shield Arrays, J. Geophys. Res., 112, 1-18, doi:10.1029/2006JB004640, 2007.

Soulat, F., Germain, O., Ruffini, G., Farrés, E., Sephton, T., Raper, I., and Kemble, S.: STERNA - A Feasability Study of PARIS Tsunami Detection - Final Report, Starlab, Barcelona, 2005.

Stein, S. and Okal, E. A.: Speed and Size of the Sumatra Earthquake, Nature, 434, 581-582, 2005.

Stosius, R., Beyerle, G., Hoechner, A., Wickert, J., and Lauterjung, J.: The Impact of GLONASS and Galileo on Tsunami Detection from Space Using GNSS-Reflectometry, Adv. Space Res., submitted, 2010.

Syndergaard, S.: On the Ionosphere Calibration in GPS Radio Occultation Measurements, Radio Sci., 35, 865-884, 2000.

Treuhaft, R. N., Lowe, S. T., Zuffada, C., and Chao, Y.: 2-cm GPS Altimetry over Crater Lake, Geophys. Res. Lett., 22, 4343-4346, 2001.

Valenzuela, G. R.: Theories for the Interaction of Electromagnetic and Ocean Waves - A Review, Bound.-Lay. Meteorol., 13, 61$85,1978$.

Voronovich, A. G.: Wave Scattering from Rough Surfaces, Springer-Verlag, Berlin, 1994.

Walker, J. G.: Satellite Constellations, J. Brit. Inter. Soc., 37, 559$571,1984$.

Wickert, J., Michalak, G., Schmidt, T., Beyerle, G., Cheng, C. Z., Healy, S. B., Heise, S., Huang, C. Y., Jakowski, N., Köhler, W., Mayer, C., Offiler, D., Ozawa, E., Pavelyev, A. G., Rothacher, M., Tapley, B., and Arras, C.: GPS Radio Occultation: Results from CHAMP, GRACE and FORMOSAT-3/COSMIC, Terr. Atmos. Ocean. Sci., 20, 35-50, doi:10.3319/TAO.2007.12.26. 01(F3C), 2009.

Wu, T., Wu, S. C., Hajj, G. A., Bertiger, W. I., and Lichten, S. M.: Effects of Antenna Orientation on GPS Carrier Phase, Manuscr. Geodaet., 18, 91-98, 1993. 